\title{
Drug interactions and adverse events in elderly heart disease patients
}

\author{
Fernanda Carolina Cruz Evangelista ${ }^{1 *}$, \\ George César Ximenes Meireles², Maria Fernanda Carvalho ${ }^{3}$ \\ ${ }^{1}$ Pharmaceutical Care Center of Autarquia Hospitalar Municipal, São Paulo, Brazil, \\ ${ }^{2}$ Interventional Vascular Service of Instituto de Assistência Médica ao Servidor Público Estadual, \\ São Paulo, Brazil, ${ }^{3}$ Board of Directors of Ambiente Medicamento, São Paulo, Brazil
}

\begin{abstract}
Chronic and multiple diseases are more prevalent in elderly individuals and, epidemiological highlight can be given to cardiovascular conditions requiring multi-drug therapies, which favor the occurrence of drug interactions. This study aims to analyze potential drug interactions and correlate them with adverse events in elderly heart-disease patients in a hospital setting. This is a prospective description of the analysis of medical prescriptions and records of 80 patients, with data collection performed by using validated instruments during a seven-month period. The drug interactions found were indicated by scientifically recognized databases and subsequently treated statistically with adequate software. 1841 potential interactions between drugs were detected, of which $74.1 \%$ did not show any therapeutic benefits, with antithrombotic and analgesic drugs accounting for the worst results. The number of potential interactions was proportional to the occurrence of adverse events, classified at $87.3 \%$ as moderate to severe. It is concluded from such results that there is a proportionality between the occurrence of potential drug interactions and the detection of adverse events, with therapeutic management being of great importance for safety, quality and affordability of the treatment.
\end{abstract}

Keywords: Drug interactions. Elderly. Heart diseases.

\section{INTRODUCTION}

Population projections by the World Health Organization show that in 2050 there will be 2.1 billion elderly in the world. Data from the Ministry of Health showed that in the last years the main cause of hospitalization of Brazilian elderly people was attributed to cardiovascular diseases (Brasil, 2016).

Combining pharmacological therapies is a usual procedure in the treatment of heart diseases and must be based on the individual characteristics and clinical response of the patient. Some combinations, however, result in undesirable interactions, adversely affecting the patient's treatment and quality of life.

*Correspondence: F. C. C. Evangelista. Instituto de Assistência Médica ao Servidor Público Estadual. Programa de Pós Graduação. Avenida Ibirapuera, 981, São Paulo. CEP: 04029-000, Brasil. Phone: (+55) 11 45738268. E-mail: fcce.mestrado@gmail.com
Drug interactions are clinical events in which the effect of a drug is changed by the presence of another drug, food or chemical agent (Brunton et al., 2010). These alterations may contribute to the treatment of concomitant diseases or generate health problems, such as the occurrence of adverse events, changes in duration of action and toxicity of a drug, new and longer episodes of hospitalization of patients (Lisboa, 2000; Tatro, 1999; Hussar, 2000). The number of medicines, gender, age, genetic characteristics, body structure and dietary habits of the patients can be a determining factor in the occurrence of interactions (Rodrigues, Oliveira, 2016; Secoli, 2010).

421 million hospital admissions worldwide are estimated, with approximately 42.7 million adverse events (Jha et al., 2013). Iyer et al. (2014) found that more than $30 \%$ of the adverse events detected in patients admitted to intensive care units were from drug interactions, many of which were preventable and predictable. 
This study aims to analyze potential drug interactions and correlate them with adverse events in elderly heart disease patients in a hospital setting.

\section{MATERIAL AND METHODS}

An observational, descriptive and prospective study, carried out at Francisco Morato de Oliveira Hospital, located in the city of São Paulo and intended for the care of state public servants and their dependents, for research and education.

\section{Population and sample}

The population was composed of patients aged 60 years or older, heart disease patients, hospitalized in a heart care unit at the study site. Patients with hospitalization period of five days or longer were included. The choice of time interval was attributed to the patients' average length of stay in the care unit and medical literature information on the increased likelihood of adverse events caused by drug interactions after such period (Strom, 2000). Patients with incomplete records, who either died or were transferred to another ward during the collection of information were excluded from the research. There were no restrictions on the number of drugs prescribed and severity of the patients' clinical status.

The medical prescriptions and records were evaluated in the wards and in the Medical Archive and Statistics Service at the study site for seven months. The choice of the period was based on the time required for the sample to be reached and on the time spent by the researcher in the institution. The information was collected after 24 hours and 120 hours of hospitalization, allowing the comparison between the moment of adjustment to the therapy and its definition.

A previous pilot study with the same methodology was conducted by the researcher to define the sample to be studied and the methodology applied.

\section{Data collection and interpretation}

The information for the research was collected by means of validated instruments previously created by Lima (2007) and Reis (2009) in similar studies containing adaptations to the terms and periods analyzed in this study. The gender, age, hospitalization diagnosis, dosages and times of administration of prescribed drugs were analyzed. Information on medical records regarding possible adverse events and laboratory test results was collected as well. The interpretation and treatment of data regarding interactions and adverse events used references from tertiary, secondary and primary sources, such as the drug monographs available in the MICROMEDEX ${ }^{\circledR}$ 2.0 database. The information obtained was subsequently compared with two other references, the MEDSCAPE ${ }^{\circledR}$ base and LEXICOMP ${ }^{\circledR}$ Online Interaction Checker. The Naranjo algorithm and the definitions used by other researchers were used to determine the causality of the adverse events detected, which received the WHO-ART terminology (Karch, Lasagna, 1975; Brasil, 2013).

\section{Statistical analysis}

The statistical analysis was performed by using the mean, median, minimum and maximum values, standard deviation, absolute and relative frequencies, as well as two-dimensional scatter plots. A 95\% confidence interval was assumed for a mean (Bussab, Morettin, 2006), generalizing the findings of the number of drugs prescribed, interactions and adverse events; Student's t-test for independent samples or Mann-Whitney (Siegel, 2006) in the comparison of total drugs prescribed after 24 hours and 120 hours of hospitalization, according to gender; analysis of variance (ANOVA) with a Fixed Factor (Neter et al., 1996) or Kruskal-Wallis in the comparison of total drugs prescribed after 24 hours and 120 hours of hospitalization, according to age group and diagnosis; Spearman's correlation coefficient in the quantification of the correlation between drug interactions and adverse events. In all conclusions obtained through the inferential analyses an alpha level of significance equal to $5 \%$ was used. Statistical analyses were carried out with the aid of statistical program $R \circledR$ version 3.3.2 (R Code Team, 2016).

\section{Ethical aspects}

The study was submitted for the examination and approval of the Research Ethics Committee of the Institute of Medical Care to State Public Servants.

\section{RESULTS AND DISCUSSION}

The research was composed of 80 elderly heart disease patients, most of them men (56.3\%), showing similarity to epidemiological data disclosed by the Ministry of Health (Brasil, 2017). The patients' average age was $74.5 \pm 7$ years, ranging from 60 to 89 years. The 
most frequent diagnoses were non-ST-Segment Elevation Acute Myocardial Infarction (50\%), Atrioventricular Block (21.3\%) and Unstable Angina (8.8\%).

During the two moments of evaluation of the selected patients, there were 1793 prescriptions of items in total, consisting of 120 different drugs. The prescriptions made contained on average 10.7 drugs after 24 hours and 11.7 drugs after 120 hours of hospitalization, which is in line with the literature that shows that the quantity of drugs prescribed is directly proportional to the patient's length of stay in the hospital unit, due to the need to adjust therapy or to complications in the clinical condition during hospitalization (Passarelli, 2005). No correlation was found between the patients' age and the quantity of drugs prescribed; differing from the diagnoses shown, in which surgical procedure for myocardial revascularization and transient ischemic attack were the ones that showed greater plurality of medicines. The female gender showed a mean of 12.1 items prescribed and greater diversity in prescription; which is similar to previous studies carried out by other researchers (Lima, 2007; Reis, 2009).

Observations regarding the positive and proportional correlation between the quantity of prescribed items and the occurrence of drug interactions were also evidenced, which is in line with the literature (Rodrigues, Oliveira, 2016; Secoli, 2010; Steinman, 2015).

The study allowed to detect 197 different interactions with 1841 potential occurrences. There was a predominance of possible drug combinations that could lead to adverse events, clinical complications and longer hospitalization. The lack of therapeutic benefit was found in 146 interactions (74.1\%) and only in 51 interactions $(25.9 \%)$ the clinical evaluation as to the feasibility of the associations showed to be necessary (Micromedex, 2017; Medscape, 2017; Lexicomp, 2015). Approximately $85.3 \%$ of the interactions identified between drugs were described simultaneously by more than one database, indicating agreement between them.

The evaluation of drug interactions between drugs showed a predominance of the pharmacodynamic nature (72.1\%), moderate severity (56\%) and unspecified onset speed (69.3\%). This highlights the need that the care team knows the drugs included in the therapy, so they can adjust dosages and posology and avoid compromising the therapeutic result. Therefore, careful consideration is required as to the feasibility of concomitant drug administrations (Micromedex, 2017). The practice of reconciliation of medicines was shown to be fundamental in the pharmacotherapeutic follow-up of the patients analyzed and must not be neglected during the patients' hospitalization process, as described in studies by other researchers (Vira, Colquhoun, Etchells, et al., 2006; Frizon, Santos, Caldeira, et al., 2014).

The therapeutic classes that showed the highest interactive potential were the antithrombotic agents (37.9\%), followed by analgesics (15.7\%), agents acting on the renin-angiotensin system $(7.8 \%)$, antidiabetic drugs (7\%), heart disease medications (6.3\%) and diuretics (4.75\%); which were also observed in Lima (2007).

Direct action on platelet aggregation, interference with insulin action and alteration in prostaglandin production and renal metabolism were the mechanisms of action most frequently elucidated by the potential drug interactions detected. The monitoring of coagulation disorders, hemodynamic stability, control of glycemic levels and renal function were the most widely suggested therapeutic management proposals in view of the potential interactions, making the health team aware of the need for therapeutic management of patients and strict monitoring of the likelihood of adverse events.

92 different types of adverse events were found, based on the WHO-ART terminology; with hypotension (11.2\%), constipation (9\%), hypertension (6\%), dyspnea $(5 \%)$, bradycardia (4.8\%) and hematomas (3.5\%) occurring more frequently.

The results obtained allowed the observation of increasing and proportional correlation regarding the number of potential drug interactions and number of adverse events detected (Figure 1). This fact can be confirmed by the estimated Spearman's correlation coefficient ( $\mathrm{s}$ ) of 0.347 ( $\mathrm{p}=0.002$ ), which allows to affirm that the higher the total drug interactions, the higher the total drug-related adverse events, in accordance with the studies conducted by Reis (2009) and Alvim et al. (2015).

Evidences were obtained regarding the quantitative relevance of the adverse events and their severity, with an emphasis on those considered as moderate and severe $(87.3 \%)$ and the causal relationship to drugs as possible and probable $(89.7 \%)$, with drug interactions standing out. The increasing and significant correlation between the severity of drug interactions and drug-related adverse events (EAM) was observed in the following situations: contraindicated interaction and mild severity EAM ( $\mathrm{s}=0.237, \mathrm{p}=0.034$ ) (Figure 2A); high severity interaction and moderate EAM $(s=0.225, p=0.045)$ (Figure 2B); moderate severity interaction and moderate $\operatorname{EAM}(s=0.383, p<0.001)$ (Figure $2 \mathrm{C})$. 
TABLE I - Summary measurements of drug interactions, their severity, nature and speed

\begin{tabular}{|c|c|c|c|c|c|c|c|}
\hline & total & mean & $\mathrm{CI}(\mathrm{mean})^{\mathrm{a}}$ & median & $\min ^{b}$ & $\max ^{\mathrm{c}}$ & $d p^{d}$ \\
\hline $\begin{array}{l}\text { Drug-drug interactions } \\
(24 \mathrm{~h}+120 \mathrm{~h})\end{array}$ & 1841 & 23.0 & $20.4 ; 25.6$ & 24.0 & 1 & 49 & 11.8 \\
\hline \multicolumn{8}{|l|}{ Severity } \\
\hline Contraindicated & 2 & 0.0 & $0.000 ; 0.044$ & 0.0 & 0 & 1 & 0.2 \\
\hline High & 745 & 9.3 & $8.0 ; 10.6$ & 9.5 & 0 & 29 & 5.8 \\
\hline Moderate & 1032 & 12.9 & $11.3 ; 14.5$ & 12.0 & 1 & 32 & 7.3 \\
\hline Mild & 62 & 0.8 & $0.6 ; 1.0$ & 0.0 & 0 & 3 & 1.0 \\
\hline
\end{tabular}

\section{Nature}

\begin{tabular}{|c|c|c|c|c|c|c|c|}
\hline Unknown & 184 & 2.3 & $1.9 ; 2.7$ & 2.0 & 0 & 8 & 1.8 \\
\hline Pharmacokinetics & 281 & 3.5 & $2.8 ; 4.2$ & 4.0 & 0 & 15 & 3.1 \\
\hline Pharmacodynamics & 1328 & 16.6 & $14.6 ; 18.6$ & 17.0 & 1 & 39 & 8.9 \\
\hline Pharmaceutics & 0 & 0.0 & - & 0.0 & 0 & 0 & 0.0 \\
\hline Pharmacokinetics and pharmacodynamics & 48 & 0.6 & $0.4 ; 0.8$ & 0.0 & 0 & 4 & 1.0 \\
\hline \multicolumn{8}{|l|}{ Speed } \\
\hline Slow & 387 & 4.8 & $4.0 ; 5.6$ & 4.0 & 0 & 17 & 3.6 \\
\hline Late & 37 & 0.5 & $0.3 ; 0.7$ & 0.0 & 0 & 6 & 1.1 \\
\hline Fast & 141 & 1.8 & $1.4 ; 2.2$ & 2.0 & 0 & 9 & 1.9 \\
\hline Unspecified & 1276 & 16.0 & $14.2 ; 17.8$ & 17.0 & 1 & 33 & 8.4 \\
\hline
\end{tabular}

${ }^{\mathrm{a}} 95 \%$ confidence interval for the mean, ${ }^{\mathrm{b}}$ minimum value, ${ }^{\mathrm{c}}$ maximum value, ${ }^{\mathrm{d}}$ standard deviation 
TABLE II - Most frequent drug interactions

\section{Medicine I}

\begin{tabular}{llll}
\hline Acetylsalicylic acid & Enoxaparin & 95 & 5.2 \\
\hline Acetylsalicylic acid & Clopidogrel & 94 & 5.1 \\
\hline Metamizole sodium & Enoxaparin & 92 & 5.0 \\
\hline Metamizole sodium & Acetylsalicylic acid & 88 & 4.8 \\
\hline Clopidogrel & Atorvastatin & 85 & 4.6 \\
\hline Clopidogrel & Enoxaparin & 81 & 4.4 \\
\hline Acetylsalicylic acid & Insulin human & 80 & 4.3 \\
\hline Metamizole sodium & Clopidogrel & 72 & 3.9 \\
\hline Acetylsalicylic acid & Atenolol & 51 & 2.8 \\
\hline Metamizole sodium & Enalapril & 49 & 2.7 \\
\hline Acetylsalicylic acid & Ranitidine & 47 & 2.0 \\
\hline Metamizole sodium & Atenolol & 45 & 2.4 \\
\hline Acetylsalicylic acid & Enalapril & 44 & 2.4 \\
\hline Enalapril & Insulin human & 37 & 2.4 \\
\hline Clopidogrel & Omeprazole & & \\
\hline & & 45 & \\
\hline
\end{tabular}

TABLE III - Summary measurements of number, severity and causality of drug-related adverse events

\begin{tabular}{lccccccc}
\hline & total & mean & CI(mean) & median & min $^{\mathbf{b}}$ & $\mathbf{m a x}^{\mathbf{c}}$ & $\mathbf{d p}^{\mathbf{d}}$ \\
\hline Drug-related adverse events & 222 & 2.8 & $2.4 ; 3.2$ & 2.5 & 0 & 11 & 1.9 \\
\hline Adverse events possibly related to DI & 214 & 2.7 & $2.3 ; 3.1$ & 2.0 & 0 & 11 & 1.9 \\
\hline
\end{tabular}

\section{Severity}


TABLE III - Summary measurements of number, severity and causality of drug-related adverse events

\begin{tabular}{lccccccc}
\hline & total & mean & $\mathbf{C I}(\mathbf{m e a n})^{\mathbf{a}}$ & median & $\mathbf{m i n}^{\mathbf{b}}$ & $\mathbf{m a x}^{\mathbf{c}}$ & $\mathbf{d p}^{\mathbf{d}}$ \\
\hline Lethal & 0 & 0.0 & - & 0.0 & 0 & 0 & 0.0 \\
\hline Severe & 40 & 0.5 & $0.3 ; 0.7$ & 0.0 & 0 & 3 & 0.8 \\
\hline Moderate & 146 & 1.8 & $1.5 ; 2.1$ & 2.0 & 0 & 7 & 1.3 \\
\hline Mild & 27 & 0.3 & $0.2 ; 0.4$ & 0.0 & 0 & 3 & 0.6 \\
\hline
\end{tabular}

\section{Causality}

\begin{tabular}{|c|c|c|c|c|c|c|c|}
\hline Defined & 1 & 0.0 & $0.000 ; 0.022$ & 0.0 & 0 & 1 & 0.1 \\
\hline Probable & 82 & 1.0 & $0.8 ; 1.2$ & 1.0 & 0 & 6 & 1.0 \\
\hline Possible & 109 & 1.4 & $1.1 ; 1.7$ & 1.0 & 0 & 6 & 1.3 \\
\hline Conditional & 21 & 0.3 & $0.2 ; 0.4$ & 0.0 & 0 & 2 & 0.5 \\
\hline Doubtful & 0 & 0.0 & - & 0.0 & 0 & 0 & 0.0 \\
\hline DRP & 1 & 0.0 & $0.000 ; 0.022$ & 0.0 & 0 & 1 & 0.1 \\
\hline
\end{tabular}

${ }^{\mathrm{a}} 95 \%$ confidence interval for the mean, ${ }^{\mathrm{b}}$ minimum value, ${ }^{\mathrm{c}}$ maximum value, ${ }^{\mathrm{d}}$ standard deviation, med $=$ medicine $\mathrm{DRP}^{*}=$ Other drug-related problems. $\mathrm{DI}=$ Drug interactions

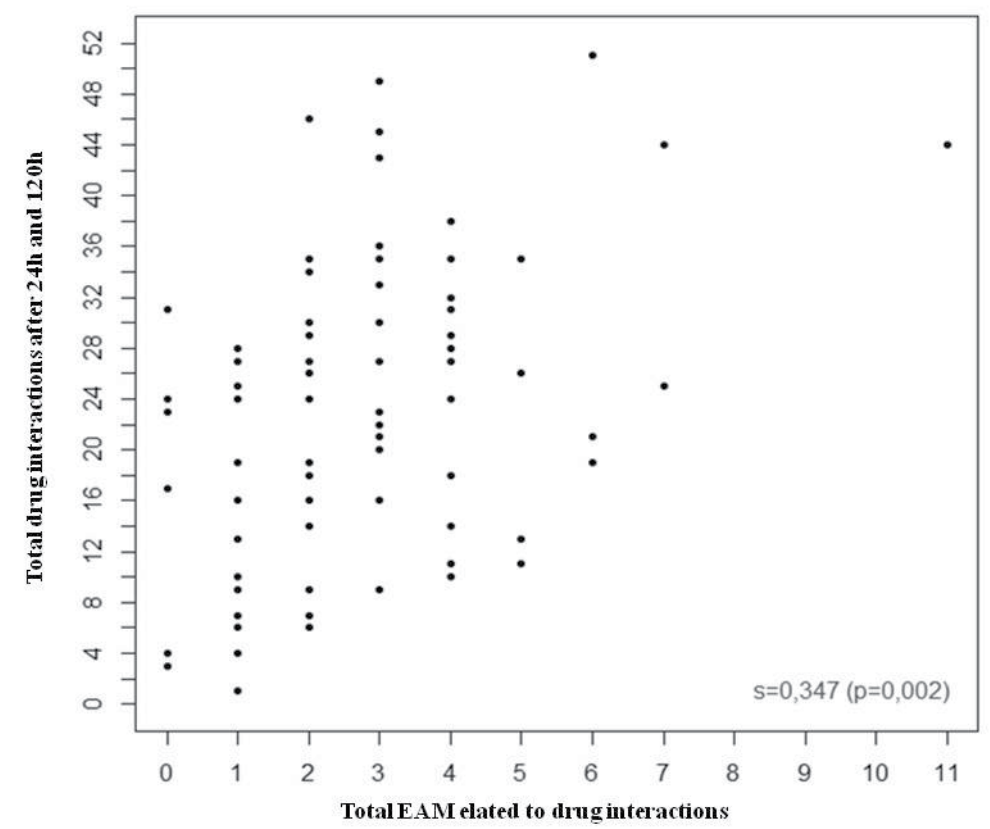

FIGURE 1 - Two-dimensional scatter plot between total drug interactions after $24 \mathrm{~h}$ and $120 \mathrm{~h}$ and total interaction-related adverse events. 
A

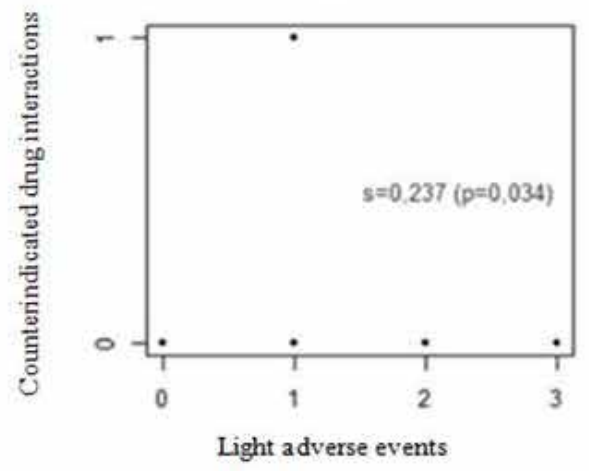

B

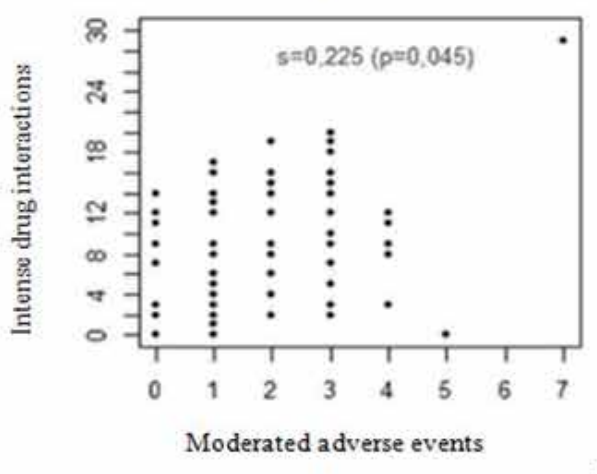

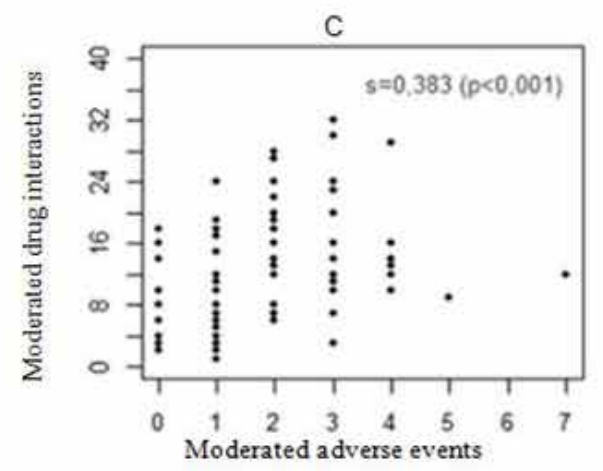

FIGURE 2 - Increasing and significant correlation between severity of drug interactions and drug-related events.

The knowledge of drug interactions and related adverse events is extremely important for the quality of health services, requiring professional qualification in selecting and interpreting such information quickly and thoroughly.

\section{CONCLUSION}

The study allowed the analysis of potential drug-drug interactions in the prescriptions for elderly heart disease patients in a hospital setting and the correspondence with adverse events. The proportionality between the quantity of drugs prescribed and the potential occurrence of drug interactions and the positive and proportional correlation between the number of interactions and adverse events were detected.

The information originated from this research enabled the preparation of an instructional material for guidance and therapeutic management of elderly heart disease patients.

\section{ACKNOWLEDGMENTS}

We thank Gianni Santos for assisting in the statistical treatments.

\section{CONFLICT OF INTERESTS}

The authors inform that there is no conflict of interest.

\section{REFERENCES}

Alvim MM, Silva LA, Leite ICG, Silvério MS. Eventos Adversos por interações medicamentosas potenciais em unidade de terapia intensiva de um hospital de ensino. Rev Bras Ter Intensiva. 2015;27(4):353-59.

Brasil. Ministério da Saúde. Investigação de Eventos Adversos em Serviços de Saúde. Brasília (DF): Ministério da Saúde, 2013. 
Brasil. Ministério da Saúde. Manual para notificação de eventos adversos e monitoramento de segurança em ensaios clínicos. Brasília (DF): Ministério da Saúde, 2016.

Brasil. Ministério da Saúde. Prêmio InovaSUS 2015: valorização de boas práticas e inovação na Gestão do Trabalho na Saúde. Brasília (DF): Ministério da Saúde, 2017.

Brunton LL, Parker KL, Blumenthal DK, Buxton ILO. Goodman \& Gilman manual de farmacologia e terapêtica. Porto Alegre: AMGH; 2010.

Bussab WO, Morettin PA. Estatística Básica. 5th ed. São Paulo: Saraiva; 2006.

Frizon F, Santos AH, Caldeira LF, Menolli PVS. Reconciliação de medicamentos em hospital universitário. Rev Enferm UERJ. 2014;22(4):454-60.

Hussar DA. Drug Interactions. In: Gennaro AR. Remington: the science and practice of pharmacy. 20th ed. Baltimore: Lippincott Williams \& Wilkins; 2000. p. 1746- 61.

Iyer SV, Harpaz R, Lependu P, Bauer-Mehren A, Shah NH. Mining clinical text for signals of adverse drug-drug interactions. J Am Med Inform Assoc. 2014;21(2):353-62.

Jha AK, Larizgoitia I, Audera-Lopes C, Prasopa-Plaizier N, Waters H, Bates DW. The global burden of unsafe medical care: analytic modelling of observational studies. BMJ Qual Saf. 2013;22(10):809-15.

Karch FE, Lasagna L. Adverse drug Reaction. A critical review. JAMA Netw Open. 1975;234:1236-41.

Lexicomp ${ }^{\circledR}$ Online. Lexi-Interact ${ }^{\mathrm{TM}}$. Hudson, Ohio: Lexicomp Inc. (1978-2015). Available from: https://online.lexi. com/lco/action/.

Lima REF. Interações medicamentosas potenciais em pacientes de Unidade de Terapia Intensiva de um Hospital Universitário do Ceará [Master's dissertation]. Ribeirão Preto: Universidade de São Paulo, Escola de Enfermagem de Ribeirão Preto; 2007.

Lisboa SML. Interações e Incompatibilidades Medicamentosas. In: Gomes MJVM, Reis AMM, organizadores. Ciências Farmacêuticas: uma abordagem em farmácia hospitalar. São Paulo: Atheneu; 2000. p. 147-63.

Medscape ${ }^{\circledR}$ LLC. Multi-Drug Interaction Checker. New York: Medscape, 2017. Available from: http://reference. medscape.com/drug-interactionchecker.
Micromedex ${ }^{\circledR}$ (electronic version). Truven Health Analytics, Greenwood Village, Colorado, USA, 2017. Available from: http://www.micromedexsolutions.com/.

Neter J, Kutner MH, Nachtsheim CJ, Wasserman W. Applied linear statistical models. 4th ed. Boston: Irwin; 1996.

Passarelli MCG. Reações adversas a medicamentos em uma população idosa hospitalizada [Doctoral thesis]. São Paulo: Universidade de São Paulo, Faculdade de Medicina; 2005.

R Code Team. $R \circledast$ : A language and environment for statistical computing, version 3.3.2. [Computer program]. Viena: $R$ Foundation for Statistical Computing, 2016. Available from: http://www.R-project.org/.

Reis AMM. Fatores associados às interações medicamentosas potenciais e aos eventos adversos a medicamentos em uma unidade de terapia intensiva [Doctoral thesis]. Ribeirão Preto: Universidade de São Paulo, Escola de Enfermagem de Ribeirão Preto, 2009.

Rodrigues MCS, Oliveira C. Interações medicamentosas e reações adversas a medicamentos em polifarmácia em idosos: uma revisão integrativa. Rev Lat Am Enfermagem. 2016; 24.

Secoli SR. Polifarmácia: interações e reações adversas no uso de medicamentos por idosos. Rev Bras Enferm. 2010;63(1):136-40.

Siegel S. Estatística não paramétrica para ciências do comportamento. 2nd ed. Porto Alegre: Artmed; 2006.

Steinman MA, Beizer JL, Dubeau CE, Laird RD, Lundebjerg NE, Mulhausen P. Beers Criteria-A Guide for Patients, Clinicians, Health Systems, and Payors. New York: American Geriatrics Society; 2015.

Strom BL. Pharmacoepidemiology. 3rd ed. Chinchester: John Wiley \& Sons; 2000. p.874.

Tatro DS. Drug Interaction Facts. St Louis: Facts and Comparisons; 1999.

Vira T, Colquhoun M, Etchells E. Reconcilable differences: correcting medication errors at hospital admission and discharge. Qual Saf Health Care. 2006; 15:122-26.

Received for publication on $01^{\text {st }}$ December 2018 Accepted for publication on $15^{\text {th }}$ September 2019 